\title{
Cooperação Sul-Sul no governo de Dilma Rousseff (2011-2016): Retração ou Transformação?
}

\section{Cooperación Sur-Sur en el gobierno de Dilma Rousseff (2011-2016): ¿retracción o transformación?}

\section{South-South Cooperation under Dilma Rousseff's government (2011-2016): Changes or Retractions?}

\author{
iD Roberto Goulart Menezes \\ Universidade de Brasília, Brasília, Distrito Federal, Brasil. \\ rgmenezes@gmail.com \\ iD) Natalia N. Fingermann \\ Universidade Católica de Santos, Santos, São Paulo, Brasil \\ nataliafinger@yahoo.com.br
}

Resumo: A política externa de Dilma Rousseff é normalmente compreendida como uma continuidade do seu antecessor, embora alguns estudos recentes tenham identificado as retrações e as transformações na agenda do Sul Global. No âmbito da Cooperação Sul-Sul (CSS), destaca-se uma escassez de análises sobre esse período. Com o objetivo de preencher essa lacuna, este artigo examina quais foram as mudanças das forças políticas domésticas que modelam a CSS, em especial, a cooperação técnica no governo de Rousseff. Para isso, define-se quatro categorias: Ideias, Instituições, Grupos de Interesses e Organização. Por meio da análise de cada uma delas, demonstra-se que as variáveis Ideias e Grupos de Interesses, além do evidente recuo da diplomacia presidencial, modelaram as transformações da cooperação para o desenvolvimento. Por fim, conclui-se que, paradoxalmente, 
o governo de Rousseff, que foi aquele que mais vinculou a CSS às questões comerciais, foi também aquele que menos atraiu os grupos de interesses locais para essas iniciativas.

Palavras-chave: Política externa brasileira. Cooperação Sul-Sul. Governo de Dilma Rousseff.

Resumen: La política exterior de Dilma Rousseff generalmente es considerada una continuación de la de su predecesor, aunque algunos estudios recientes han identificado la reducción y las transformaciones en la agenda del Sur Global. En la Cooperación Sur-Sur(CSS) hay una escasez de análisis en este período. Para llenar ese vacío, este artículo examina los cambios en las fuerzas políticas internas que dan forma a la CSS, especialmente la cooperación técnica en el gobierno de Rousseff. Para ello, se definen cuatro categorías: Ideas, Instituciones, Grupos de Interés y Organización. A través de un análisis de cada una de ellas, se muestra que las variables Ideas y Grupos de Interés, además del evidente retroceso de la diplomacia presidencial, dieron forma a las transformaciones de la cooperación para el desarrollo. Finalmente, se concluye que, paradójicamente, el gobierno de Rousseff fue el que más relacionó el CSS con las cuestiones comerciales, bien como el que menos atrajo a los grupos de interés locales a esas iniciativas.

Palabras clave: Política externa brasileña. Cooperación Sur-Sur. Gobierno de Dilma Rousseff.

Abstract: The foreign policy of Dilma Rousseff has been usually seen as a part of a continuum of her predecessor, although some recent studies have identified retractions and changes in the Global South agenda. There is a lack of analysis of South-South Cooperation (SSC) during this period. In order to fill this gap, this article examines the changes of political domestic forces shaping SSC, particularly, technical cooperation in Rousseff's government. For this purpose, four categories were defined: ideas, institutions, groups of interests and organization. By analyzing each one of them, the study has identified that two variables, ideas and groups of interests, besides the evident retreat of presidential diplomacy, 
have shaped the shifts in Brazilian development cooperation. Finally, it has concluded that although Rousseff's government has tied South-South Cooperation to commercial interests, the groups of interests have not taken a part of SCC initiatives.

Keywords: Brazilian foreign policy. South-South cooperation. Dilma Rousseff's government.

Data de recebimento do artigo: 01/03/2019

Data de aprovação do artigo: 27/05/2019 
Cooperação Sul-Sul no governo de Dilma Rousseff (2011-2016)...

Roberto Goulart Menezes • Natalia N. Fingermann

\section{Introdução}

Durante os governos de Lula da Silva (2003-2010), as relações Sul-Sul constituíram um dos eixos de orientação da política externa do Brasil. Essa opção por adensar as relações diplomáticas com os países do Sul permaneceu nos governos de sua sucessora, Dilma Rousseff (2011-2016)ํ. De modo geral, a política externa brasileira entre 2003 e 2016 tem sido tratada como um continuum. Uma parte da literatura que analisa esse período da agenda externa brasileira destaca que o elemento central para reforçar o argumento da continuidade é a influência exercida pelo Partido dos Trabalhadores (PT) nesta área.

De acordo com o discurso oficial do governo, a aproximação e o aprofundamento das relações internacionais do Brasil com os demais países do Sul desde 2003 era necessária tanto para ampliar a presença do país no mundo, quanto para fortalecer a multipolaridade no sistema internacional. Assim, o objetivo dessa estratégia Sul-Sul era projetar o Brasil como o país "que entende o desenvolvimento como instrumento de promoção de estabilidade e do equilíbrio global" (CORRÊA, 2010, p. 177).

Essa postura do governo em favor de uma maior autonomia internacional, aliada a um projeto de desenvolvimento doméstico, gerou divergências entre os acadêmicos e especialistas de política externa. Por um lado, emergem autores críticos do foco no Sul Global que argumentam que a política externa desse período não passou de um mecanismo de ideologização das relações internacionais devido à influência do Partido dos Trabalhadores nas gestões de Lula e Rousseff (ALMEIDA, 2007, 2010, 2014). Segundo essa corrente, os ganhos oriundos das relações comerciais junto àqueles países do Sul não foram significativos e demonstram que "a política externa dos governos do PT (2003-2015), focada na Cooperação Sul-Sul, foi um fracasso no que se refere ao comér-

1 A presidenta Dilma Rousseff foi afastada do cargo em 12 de maio de 2016. O processo de impeachment teve início em 2 de dezembro de 2015 na Câmara de Deputados e culminou com a cassação do seu mandato pelo Senado em 31 de agosto de 2016. 
Cooperação Sul-Sul no governo de Dilma Rousseff (2011-2016)...

Roberto Goulart Menezes • Natalia N. Fingermann

cio de bens na dimensão bilateral [...] particularmente evidente no caso dos países-membros do Mercosul." (GONÇALVES, 2016, p. 3).

Por outro lado, surge uma corrente de autores que considera acertada a estratégia Sul-Sul, porém diferem a ênfase dada na gestão de Lula e Rousseff, ao mesmo tempo em que destacam, principalmente, os ganhos não econômicos do discurso solidário e cooperativo, com ênfase na maior participação do Brasil em espaços de articulação internacional, seja do Norte (G-20 financeiro, OMC e ONU), seja do Sul (BRICS, IBAS, UNASUL, entre outros). Mariano et al. (2015), por exemplo, apontam que entre 2003 e 2015 houve avanços significativos na inserção internacional do Brasil, embora para eles seja preciso diferenciar a atuação dos governos de Lula da atuação de Rousseff, pois, no primeiro momento, havia uma política externa "altiva e ativa" com um forte discurso sobre laços de solidariedade e interdependência entre os países do Sul. Nessa mesma linha, Cervo e Lessa (2015) ressaltam o papel do governo Lula na construção desse novo paradigma de base Sul-Sul para a política externa, mostrando, em seguida, as dificuldades e retrocessos da gestão de Rousseff pela inexistência de "ideias forças" no governo para movimentar os diversos atores da sociedade e do próprio Estado.

No caso da Cooperação Sul-Sul (CSS), em especial, a cooperação técnica, é importante apontar a centralidade que ela ganha no bojo desse novo paradigma das relações internacionais, uma vez que esse mecanismo se torna chave para a construção de espaços de diálogo e solidariedade, pela transferência de conhecimento, entre os países do Sul Global. Dessa forma, logo surge um debate sobre essa temática específica que diverge, principalmente, em relação às motivações do governo brasileiro. Nesse sentido, os autores apresentam aos menos três diferentes explicações - altruístas, autointeressada e imperialista - sem tratar de diferenciar o andamento da cooperação técnica nas gestões de Lula da Silva e Rousseff (FINGERMANN, 2014; 2015; CABRAL; SHANKLAND, 2013; MENEZES; RIBEIRO, 2010; RIBEIRO, 2010; VIGEVANI; CEPALUNI, 2007; LIMA, 2005). 
Cooperação Sul-Sul no governo de Dilma Rousseff (2011-2016)...

Roberto Goulart Menezes • Natalia N. Fingermann

Com o propósito de preencher essa lacuna e contribuir com o debate acadêmico em torno da CSS, este artigo busca analisar especificamente quais foram as mudanças da CSS e, principalmente, da cooperação técnica durante os governos (2011-2016) de Dilma Rousseff. Para isso, na primeira parte do estudo, discute-se um panorama das mudanças desencadeadas no cenário internacional, principalmente após a crise de 2008, com impactos significativos na agenda do Sul Global. Em seguida, apresenta-se uma análise da esfera doméstica, com adaptações no marco teórico estabelecido por Lancaster (2007), que identifica quatro variáveis: Ideias, Instituições, Grupos de Interesse e Organizações, que moldam a cooperação para o desenvolvimento internacional. Por fim, o artigo conclui que o governo de Rousseff faz uma sutil mudança nas ideias por trás da CSS e da cooperação técnica, ao vinculá-las às questões de cunho comercial e investimento, enquanto a $A B C$ reforça nesse período a proposta de fortalecimento da modalidade de cooperação trilateral, que une cooperação Sul-Sul à cooperação tradicional do Norte. Além disso, o estudo mostra que o low profile da presidenta na política externa, somado aos descompassos de seus governos com grupos de interesses domésticos, inviabiliza a efetividade de se incluir essa agenda mais comercial na cooperação técnica. De maneira que o resultado efetivo do governo de Rousseff para a cooperação técnica fica restrito à expansão e fortalecimento dos projetos de cooperação trilateral, que foi uma agenda incluída pela própria $A B C$ para lidar com um momento de retração orçamentária e dificuldades organizacionais.

\section{O Brasil e as relações com o Sul Global após a crise de 2008}

Entre 2003 e 2008, o Brasil e os demais países sul-americanos foram beneficiados pela valorização das commodities minerais, energéticas e agrícolas no mercado mundial. Esse período de re- 
lativa bonança, embora curto, tem sido identificado na literatura como "superciclo" das commodities e contribui para aquecer as economias da região. Nesse período, a China foi o principal destino das exportações de produtos agroindustriais, metais e hidrocarbonetos. Essa demanda por recursos naturais e energéticos pelo colosso chinês fortaleceu o caixa dos países e contribuiu para a ampliação da "margem de autonomia das economias da América do Sul" (CEPAL, 2016, p. 14). Porém, esse período de valorização das commodities começou a declinar a partir da crise financeira de 2008.

A retração do cenário econômico até então favorável à região começou a reverter-se de vez em 2012 e levou a derrubada dos preços das commodities. Desde então, quase todas as regiões do mundo, com poucas exceções, têm apresentado baixo crescimento econômico. A China que assumiu a posição de segunda economia mundial registrou, em média, crescimento de $10 \%$ ao ano até 2012 e cerca de 7\% nos seguintes. A desaceleração econômica dos Estados Unidos, Europa e Japão contrasta inicialmente com o dinamismo chinês e reforça sua ascensão como potência econômica e geopolítica na ordem internacional.

Entre as denominações utilizadas para referir-se ao lugar das nações não centrais na ordem geopolítica contemporânea, destaca-se a noção de Sul Global. Essa noção é parte do processo de construção política do Sul e seu emprego foi impulsionado pelas transformações geopolíticas e econômicas na ordem mundial com a ascensão pacífica da China e acompanhada por Índia, Brasil, Rússia e demais países da semiperiferia (DOMINGUES, 2013). Do ponto de vista geopolítico, a crise financeira global de 2008 nos centros do capitalismo contemporâneo realçou o papel político e econômico dessas nações no contexto da reforma da arquitetura financeira e monetária internacional (notadamente no FMI) e da crescente influência destes no G-20 financeiro.

Aqui, o Sul Global não é apenas entendido como heterogêneo, multifacetado e de difícil apreensão política e teórica. Ele se inscreve na modernização global e abarca as três regiões da moder- 
Cooperação Sul-Sul no governo de Dilma Rousseff (2011-2016)...

Roberto Goulart Menezes • Natalia N. Fingermann

nidade: América Latina, Ásia (com destaque especial para China e Índia) e África (DOMINGUES, 2013), que detêm quase metade do Produto Nacional Bruto mundial. O caráter heterogêneo do Sul Global se expressa pela assimetria econômica e política das nações que o compõem e pelo respectivo poder infraestrutural ou capacidade estatal de cada uma delas. Assim, podemos identificar a existência de um Sul Forte, integrado por nações das três regiões que compõem a semiperiferia e possuem uma estratégia de inserção internacional ativa, bem como "alguma capacidade de contribuir para a gestão da ordem internacional em termos regionais ou globais" e "algum grau de coesão interna e capacidade de ação estatal efetiva" (HURRELL, 2006, p. 1). Em oposição, o Sul Fraco é composto por diversas periferias (anexada, explorada, solta), convivendo permanentemente à sombra da chamada "desconexão forçada" (CHESNAIS, 1996).

No Brasil, poucos meses após Dilma Rousseff assumir a presidência, em 2011, o País passou a sofrer mais diretamente os efeitos da crise internacional. Desencadeada em setembro de 2008, após a falência do banco de investimentos Lehman Brothers, a crise provocou uma sucessão de quebras na economia dos Estados Unidos. A crise financeira não ficou circunscrita ao território norte-americano. Em poucas semanas, essa turbulência varreu o globo e atingiu em cheio a Europa e pôs o Euro à prova. A China, que até então havia mantido as taxas de crescimento mundial, adota uma postura de precaução e foca seus esforços no mercado doméstico, com impactos significativos nas diversas economias do mundo.

Em resposta a esse novo cenário internacional adverso, o governo de Rousseff adotou uma política econômica anticíclica de caráter desenvolvimentista que incluiu, entre outras ações: a redução dos juros, uso intensivo do BNDES, aposta na reindustrialização, desonerações, plano para infraestrutura, reforma do setor elétrico, desvalorização do real, controle de capitais e proteção ao produto nacional (SINGER, 2015). O fato é que essa nova configuração política desenhada por Rousseff gerou impacto nos grupos de interesses, principalmente, entre parcelas do empresariado, que 
Cooperação Sul-Sul no governo de Dilma Rousseff (2011-2016)...

Roberto Goulart Menezes • Natalia N. Fingermann

nos anos seguintes, até o impedimento da presidente em 2016, passaram a resistir à política econômica do governo. E, no caso da CSS e cooperação técnica, passaram a não integrar as vontades presidenciais de angariar ganhos comerciais e investimentos por meio da Cooperação Sul-Sul. No gráfico 1, tem-se a variação do PIB entre 2006-2016:

Gráfico 1 - Variação do Produto Interno Bruno (PIB) brasileiro (2006-2016)

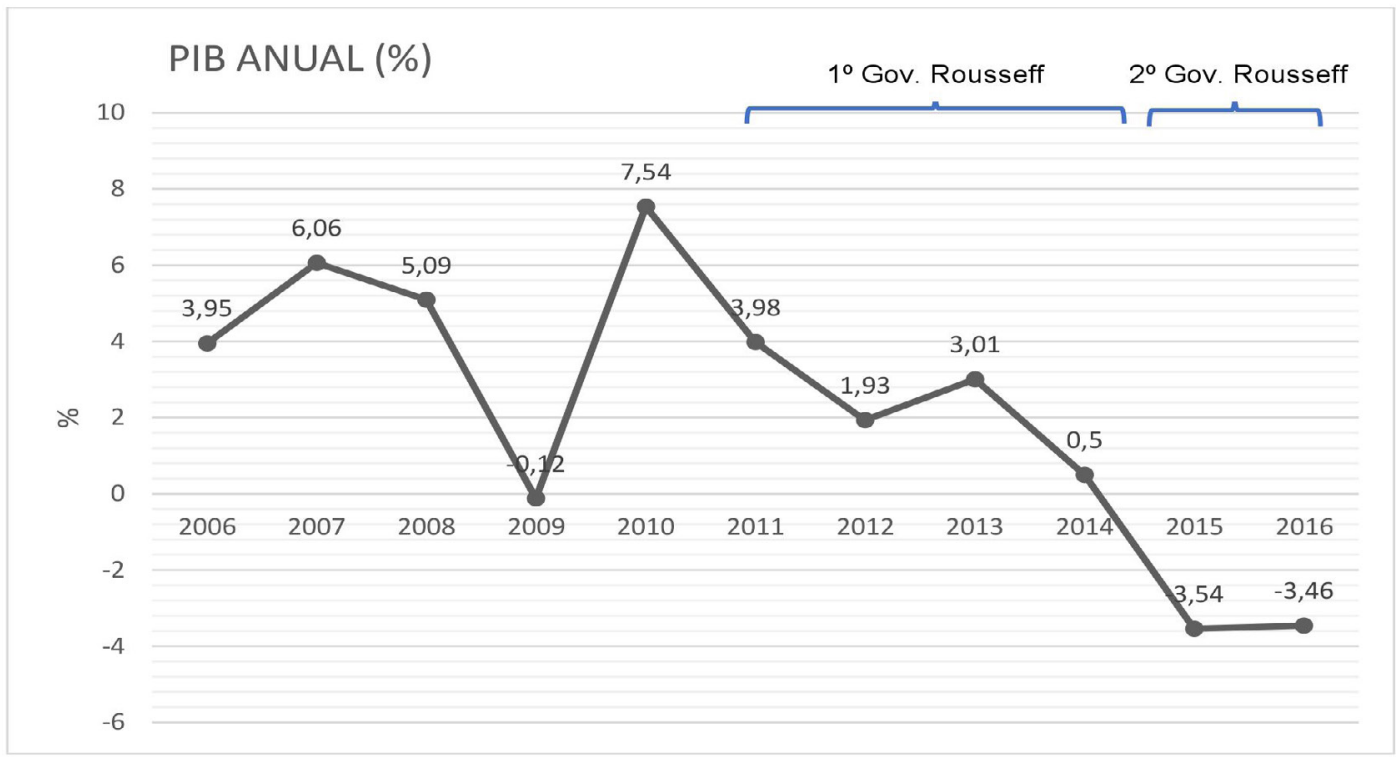

Fonte: Elaboração própria com base nos dados do Banco Mundial (2018).

Fonte: SOUZA, 2018, p. 106.

A partir de 2012, o Brasil passa a sentir mais diretamente os efeitos da crise de 2008 em função da retração das economias centrais e a desaceleração do crescimento chinês. As eleições presidenciais ocorreram em um cenário de crise da economia brasileira. Rousseff conseguiu se reeleger no segundo turno, mas com uma pequena margem de vantagem sobre seu adversário. Em janeiro de 2015, a presidente Dilma Rousseff iniciou seu segundo mandato com uma plataforma econômica oposta à que tinha sido defendida no período eleitoral. A nomeação de Joaquim Levy para o Ministério da Fazenda representou a opção pela agenda da ortodoxia neolibe- 
Cooperação Sul-Sul no governo de Dilma Rousseff (2011-2016)...

Roberto Goulart Menezes • Natalia N. Fingermann

ral. De acordo com ele, para tirar o Brasil da crise seria necessário reformar a previdência social, rever benefícios e demais programas sociais, privatizar, reformar o Estado entre outras políticas que conformam os conhecidos programas de ajustes estruturais. Essa agenda ortodoxa acabou encampada pela presidenta Rousseff como necessária e inadiável para o desenvolvimento sustentável. Não teve uma reedição da Carta ao Povo Brasileiro de 2002, mas o Partido dos Trabalhadores pouco se opôs a essa política de ajuste.

O fato é que com essa agenda econômica o Governo Rousseff não atingiu seus objetivos de crescimento econômico e o desgaste político já era evidente no segundo semestre de 2015. A presidenta passou a despender praticamente toda a energia política de seu governo com as questões domésticas e, sobretudo, tentando debelar a crise política com o Congresso Nacional a fim de manter-se no cargo. Não sobrando quase nenhum espaço para a agenda internacional. A seguir, examina-se esse ponto em mais detalhes por meio da análise das forças domésticas que influenciam na cooperação para o desenvolvimento internacional.

\section{Cooperação Sul-Sul nos Governos de Dilma Rousseff}

A eleição de Dilma Rousseff em 2010 gerou nos analistas de relações internacionais expectativas positivas sobre a agenda de projetos de Cooperação Sul-Sul (LEITE, 2010). Considerando que a presidenta representava uma continuidade, em linhas gerais, da agenda de política externa do ex-presidente Lula da Silva (20032010), na qual a estratégia de cooperação para o desenvolvimento fazia parte do projeto de inclusão do Brasil em outros espaços de articulação internacional. Além disso, o esforço em se manter uma política de transparência dos recursos utilizados nessa área por meio da publicação do COBRADI (Cooperação brasileira para o desenvolvimento internacional) em 2013 e 2016 aparentemente si- 
Cooperação Sul-Sul no governo de Dilma Rousseff (2011-2016)...

Roberto Goulart Menezes • Natalia N. Fingermann

nalizava que a Cooperação Sul-Sul passaria a ser concebida como uma política de Estado.

Entretanto, as expectativas iniciais logo não se confirmaram. O primeiro indício dessa mudança se deu com os cortes orçamentários na CSS. De acordo com o IPEA (2016; 2018), o montante total destinado à CSS passou de R\$985,2 milhões em 2011 para R\$ 366,6 milhões em 2015². Em relação à cooperação técnica ${ }^{3}$, é possível verificar que a Agência Brasileira de Cooperação (ABC) também sofreu uma redução orçamentária, com um corte de mais de $\mathrm{R} \$ 10$ milhões de reais no ano de 2013 em comparação ao ano de 2011, revertido em seguida no ano de 2015, quando o orçamento retornou ao patamar de $\mathrm{R} \$ 60$ milhões anuais.

Embora a queda orçamentária da cooperação técnica seja difícil de analisar devido às mudanças contábeis realizadas nas três publicações do IPEA (2013; 2016; 2018), os dados consolidados da CSS indicam o enfraquecimento dessa ferramenta de manutenção das relações Sul-Sul durante a gestão de Rousseff. Estudiosos da área apontam que houve um desvio da "grande estratégia no caminho da transição entre Lula e Dilma" (LIMA; MILANI, 2016, p. 37), pois houve "refluxo da atuação brasileira nas agendas de CSS com viés geopolítico" (Ibid, 2016, p. 37). Essa mudança na CSS que tinha sido até então uma das principais ferramentas da política externa precisa ser analisada de forma mais sistemática para se compreender qual formato ela abarca no período da presidência de Dilma Rousseff.

Para realizar essa empreitada, este artigo inspira-se no constructo teórico apresentado por Carol Lancaster (2007), em seu livro Foreign Aid: Diplomacy, Development and Domestic Politics, que define quatro categorias de forças políticas domésticas que modelam a ajuda internacional: Ideias, Instituições, Grupos de Interesses e Organização. Para cada uma dessas categorias, a autora traça os

\footnotetext{
2 Na análise, retira-se o valor despendido no ano de 2016. Pois, há um salto dos gastos do governo federal em CSS para R\$ 3,1 bilhões de reais devido exclusivamente ao pagamento de dívidas realizadas a organismos internacionais durante a gestão do presidente Michel Temer (IPEA, 2018).

3 É importante apontar a dificuldade de se analisar os cortes dentro da categoria de cooperação técnica, entre o período de 2014-2016, uma vez que a publicação do IPEA (2018) não estabelece as mesmas categorias dos relatórios anteriores (IPEA, 2013; 2016). Dessa maneira, o artigo traz aqui somente os dados referentes ao orçamento da ABC que é apresentado nos três relatórios.
} 
Cooperação Sul-Sul no governo de Dilma Rousseff (2011-2016)...

Roberto Goulart Menezes • Natalia N. Fingermann

aspectos relevantes para o estudo da cooperação para o desenvolvimento internacional em países desenvolvidos ${ }^{4}$, os quais devem ser adaptados no caso da análise da Cooperação Sul-Sul, provida pelo Brasil, que, como um país do Sul Global, possui características próprias de sua realidade. A primeira categoria, Ideias, refere-se às visões de mundo e às crenças baseadas nos princípios que permeiam o Estado. As visões de mundo, chamadas "worldviews", são "shared values (based on culture, religion and ideology) about what is right and wrong, appropriate and inappropriate in public and private life" (LANCASTER, 2007, p. 18). São essas visões de mundo que estabelecem as normas sociais ou "principled beliefs" da sociedade. Nesse sentido, as visões de mundo e as normas sociais são pontos-chave na manutenção ou retração da ajuda internacional, uma vez que quando há consenso em relação às ideias de solidariedade entre os povos no seio da sociedade, a ajuda internacional tende a se ampliar. Por outro lado, em momentos que visões de mundo mais liberais se tornam majoritárias, a ajuda internacional tende a minguar.

Em relação às Instituições, a autora define que são aquelas instituições políticas que estabelecem as regras do jogo político e destaca os seguintes aspectos: as regras eleitorais, o papel do legislativo no sistema presidencial versus o sistema parlamentar, o papel dos governos locais e das entidades semipúblicas, como os comitês consultivos e as Organizações Não Governamentais patrocinadas pelo Estado. De acordo com Lancaster, as regras eleitorais podem afetar indiretamente a agenda da ajuda internacional, principalmente em países de representação proporcional que produzem um maior número de partidos políticos, com a necessidade de se formar uma coalizão presidencial. Nesse caso, a questão da ajuda internacional pode ser impactada quando o tema é relevante a um dos partidos políticos da coalizão, que torna a questão uma moeda de troca no momento da formação da coalizão. Sobre o papel do legislativo, a autora destaca que a relação entre o Legislativo e o Executivo em sistemas presidencialis-

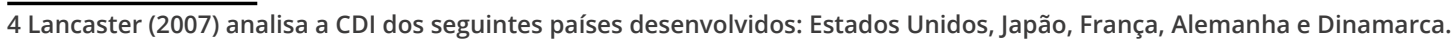


Cooperação Sul-Sul no governo de Dilma Rousseff (2011-2016)...

Roberto Goulart Menezes • Natalia N. Fingermann

tas é a chave para a manutenção ou retração da cooperação para o desenvolvimento internacional, assim como coloca que a sua atuação ativa pode também levar "aid issues to public attention and debate and act [...] as venues to inform the public and create national consensus on aid" (LANCASTER, 2007, p. 20). Por último, Lancaster (2007) ressalta a importância de se olhar para o papel dos governos subnacionais, das entidades semiestatais e comitês consultivos na formulação da agenda da ajuda internacional devido ao seu acesso especial em relação aos policymakers, que afeta diretamente os propósitos e a condução da ajuda internacional. No caso brasileiro, esse artigo inclui dentro deste escopo as autarquias, como a EMBRAPA e a Fiocruz, pois nota que a centralidade desses organismos na execução da cooperação técnica denota a eles a capacidade de influenciar também a própria formulação da CSS, consagrando conceitos como a ideia de "cooperação estruturante" (ALMEIDA et al., 2010).

Os grupos de interesses referem-se às forças políticas que pressionam em relação à alocação de recursos da ajuda internacional. Lancaster (2007) delineia três tipos de grupos de interesses: os apoiadores do viés comercial da ajuda internacional, as Organizações Não Governamentais e os apoiadores do viés desenvolvimentista e solidário e os Grupos com afinidade específica a países, grupos religiosos, comunidades linguísticas, entre outros. No caso do primeiro grupo, a representação é normalmente ligada a Associações Industriais e Comerciais ou Câmaras de Comércio, como a Confederação Nacional da Indústria (CNI), Federação das Indústrias do Estado de São Paulo (FIESP), entre outras. Já no segundo, são normalmente think tanks (laboratórios de ideias), Organizações Não Governamentais (ONGs) e/ou movimentos sociais, como no Brasil pode-se nomear principalmente a atuação da ONG FASE, do Movimento dos Sem-Terra (MST) e da Comissão Pastoral da Terra na cooperação técnica, sem incluir, nesse momento, uma análise das comunidades linguísticas, tal como a Comunidade dos Países de Língua Portuguesa. 
Por fim, a autora (2007) identifica a categoria organização, a qual para ela está ligada a estrutura organizacional da ajuda internacional dentro do aparato estatal. Segundo a autora, quanto maior o grau de autonomia institucional da agência de cooperação para o desenvolvimento internacional do Executivo, maior a probabilidade de a agência atingir, por meio de uma estratégia de lobby e advocacy, os seus próprios interesses. No Brasil, é preciso analisar a Agência Brasileira de Cooperação (ABC) e seu grau de autonomia frente ao Ministério das Relações Exteriores e a Presidência da República. Em seguida, analisam-se as transformações em cada uma dessas forças motrizes no caso do Brasil durante o governo de Rousseff.

\subsection{Ideias}

No Brasil, as visões de mundo que afetam positivamente ou negativamente a cooperação para o desenvolvimento internacional são ligadas ao debate que há sobre a capacidade de atuação do Estado e ao grau de autonomia internacional. A capacidade de atuação do Estado para lidar com as questões de cunho político, econômico e social varia entre um viés neoliberal e um desenvolvimentista. Para o viés neoliberal, o Estado deve ter um papel mínimo e permitir que as forças do livre mercado atuem sem "amarras". Já, no caso do viés desenvolvimentista, o Estado é um ator central na busca do desenvolvimento econômico e social, e através de políticas públicas busca mitigar a pobreza e as desigualdades sociais. A questão do grau de autonomia internacional também é chave nesse processo, pois duas posições distintas competem entre si. Por um lado, há um grupo que entende que o Brasil deve manter uma relação especial com os Estados Unidos e, por outro lado, há aqueles que defendem uma maior autonomia internacional, com a adoção de uma estratégia de "autonomia pela diversificação", dentro da qual "a cooperação Sul-Sul [visa] buscar maior equilíbrio com os países do Norte, realizando ajustes, aumentando o 
Cooperação Sul-Sul no governo de Dilma Rousseff (2011-2016)...

Roberto Goulart Menezes • Natalia N. Fingermann

protagonismo internacional do país e consolidando mudanças" (VIGEVANI; CEPALUNI, 2007, p. 283).

No caso dos governos de Lula e Rousseff, o viés desenvolvimentista ${ }^{5}$ na esfera doméstica esteve vinculado ao entendimento de ampliar a autonomia internacional. O governo Lula vinculou o “novo acervo de políticas sociais que atacam a pobreza e a desigualdade no plano doméstico com uma ativa diplomacia presidencial. Ao mesmo tempo em que se transformou a questão social numa bandeira de política externa" (HIRST; SOARES DE LIMA; PINHEIRO, 2010, p. 6). Assim, formula-se na CSS brasileira um discurso oficial que destaca como seus princípios norteadores a solidariedade, a reciprocidade e a não intervenção apresentando-se como não sendo um fim em si mesmo. Na gestão de Lula, esses princípios são reforçados claramente em discursos oficiais do presidente e de Celso Amorim, então Ministro das Relações Exteriores, para quem o objetivo da CSS é "[...] transformar os laços de amizade (...) em progresso econômico e social, em benefício mútuo" (AMORIM, 2003).

Nos governos de Rousseff, a visão de mundo de cunho desenvolvimentista, os princípios norteadores da CSS e a orientação do Sul para política externa são mantidos, porém, ajustes nesse momento são feitos pela presidenta e o Ministro das Relações Exteriores (ANTÔNIO PATRIOTA, 2011-2013). Segundo Marcondes e Mawdsley (2017), os ajustes apresentados pelo governo Rousseff indicam que a lógica da CSS passou a ser considerada por um viés mais comercial e menos altruísta. Em certa medida, esse ajuste nas ideias permeando a CSS fica evidente quando o governo faz uma declaração na qual sugere a substituição da Agência Brasileira de Cooperação pela criação da Agência Brasileira de Cooperação e Desenvolvimento, intenção que depois foi confirmada pelas palavras de Antônio Patriota, ao afirmar que seria uma "transformação estrutural", com a inclusão da agenda de atração de investimentos (FOLHA S. PAULO, 2013).

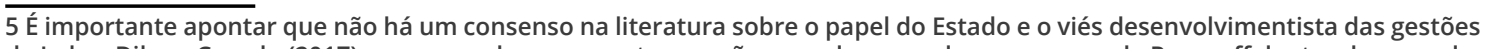
de Lula e Dilma. Curado (2017), por exemplo, argumenta que não se pode enquadrar o governo de Rousseff dentro do novo-desenvolvimentismo, embora tenha tido uma atuação importante do Estado. 
Cooperação Sul-Sul no governo de Dilma Rousseff (2011-2016)...

Roberto Goulart Menezes • Natalia N. Fingermann

No encontro de celebração dos 50 anos da União Africana, realizado na Etiópia, em 2013, Rousseff também apresenta essa proposta de reformar a cooperação técnica, com a criação da agência e o estabelecimento de elos entre a CSS e a expansão do investimento e expansão comercial. De acordo com a ex-presidenta, a anulação de US\$900 milhões da dívida de países africanos ${ }^{6}$ foi uma forma de conseguir estabelecer novas rodadas de negociações, em que se possa "financiar empresas brasileiras nos países africanos e também relações comerciais que envolvam maior valor agregado [...]. Então o sentido é uma mão dupla: beneficia o país africano e beneficia o Brasil" (BBC, 2013). A decisão política de anular dívidas, como nesse caso, é para que o país devedor possa contrair novos créditos junto ao Brasil e assim comprar mercadorias no País. É uma forma de desbloquear as relações comerciais de países de menor desenvolvimento relativo.

Embora a mudança da agência não tenha se efetivado, é importante apontar essa alteração sutil que houve no âmbito das ideias, pois foi a primeira vez que o governo começou a estabelecer um vínculo entre cooperação Sul-Sul e investimento, que até então não havia sido feito. Em Moçambique, no caso do Programa ProSAVANA7, por exemplo, houve a tentativa de se firmar esse vínculo entre a esfera comercial e investimento e a cooperação técnica, quando realizou-se o lançamento do Fundo Nacala ${ }^{8}$, com a proposta de atrair mais de US\$500 milhões de investidores privados para o desenvolvimento agrário da região localizada no norte de Moçambique. Contudo, a rejeição dessa narrativa por organizações da sociedade civil fez com que o governo brasileiro e a própria FGV Projetos retrocedessem na iniciativa (FINGERMANN, 2014; 2015; 2017b).

\footnotetext{
6 Os países africanos beneficiados foram: República do Congo, Costa do Marfim, Tanzânia, Gabão, Senegal, República da Guiné, Mauritânia, Zâmbia, São Tomé e Príncipe, República Democrática do Congo, Sudão e Guiné Bissau.

7 O Programa ProSAVANA, é o maior programa de Cooperação Trilateral da ABC, em parceria com JICA e o Governo de Moçambique, com objetivo de estabelecer novos modelos de desenvolvimento agrícolas na região do Corredor de Nacala, ao Norte de Moçambique.

8 Fundo Nacala era uma iniciativa da GVAgro da FGV Projetos, lançada em julho de 2012, com o apoio direto da coordenação do ProSAVANA. A gestão do Fundo é da FGV Projetos em conjunto com a empresa 4I. Green, e tem o objetivo de atrair investimentos para o desenvolvimento agrário da região.
} 
Cooperação Sul-Sul no governo de Dilma Rousseff (2011-2016)...

Roberto Goulart Menezes • Natalia N. Fingermann

Outro aspecto que indica adequações na esfera das ideias, porém sem participação direta da presidência, e com a liderança da própria $A B C$ é o enfoque dado para a modalidade de cooperação trilateral, a qual une os esforços da CSS àqueles da cooperação do Norte. Embora muitos projetos de cooperação trilateral tenham emergido ainda durante o mandato de Lula da Silva, é no governo de Rousseff que essa modalidade se consolida dentro da estratégia da $A B C$. Pois, como afirma o Embaixador Fernando Abreu (2013), ex-Diretor da ABC, o Brasil:

Tem assumido compromissos crescentes nessa área, por entender que a cooperação triangular permite ampliar a escala e o impacto da cooperação Sul-Sul brasileira. Na cooperação triangular, unem-se os esforços dos dois parceiros externos, favorecendo a otimização do uso de recursos financeiros, humanos e de infraestrutura. (ABREU, 2013, p.12)

A opção pela Cooperação Trilateral também pode ser vista a partir da elaboração de protocolos e padronização de instrumentos entre a $A B C$ e os parceiros da cooperação tradicional, tais como: o "Marco Estratégico de Parceria Trilateral para o Desenvolvimento", criado em 2012 pela ABC e USAID; “Diretrizes para Iniciativas de Cooperação Sul-Sul Trilateral Brasil - UNICEF" estabelecido em 2013 pela ABC e UNICEF; "Manual Operacional da Cooperação Trilateral Brasil-Alemanha", estabelecido em 2015 pela ABC e GIZ, e "Diretrizes Gerais para a Concepção, Coordenação e Supervisão de Iniciativas de Cooperação Trilateral", desenvolvido em 2017 pela $\mathrm{ABC}^{9}$.

Além disso, vale destacar o incremento significativo que há na alocação de recursos da cooperação trilateral durante a gestão de Rousseff. Conforme Abreu (2013), no ano de 2013, havia 37 projetos de cooperação trilateral, que representavam um orçamento de US\$ 54 milhões, dos quais 45\% (US\$24,3 milhões) eram financiados exclusivamente pela $A B C$, e correspondiam a uma quantia

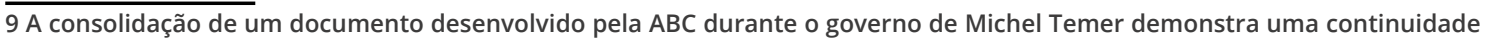
dessa estratégia de expansão dos projetos de Cooperação Trilateral. 
Cooperação Sul-Sul no governo de Dilma Rousseff (2011-2016)...

Roberto Goulart Menezes • Natalia N. Fingermann

muito maior do que os recursos destinados à cooperação técnica bilateral, US\$8,3 milhões, para o mesmo período. Esse foco na cooperação trilateral é internalizado pela gestão subsequente de Temer, a qual inclui essa categoria de maneira separada no relatório do IPEA, publicado em 2018.

\subsection{Instituições}

No Brasil, o poder Executivo é a instituição política que define a política externa do País com o auxílio do Ministério das Relações Exteriores. O Legislativo, embora se envolva pouco com os temas internacionais, é responsável por analisar e deliberar sobre os atos internacionais do País. No caso do governo de Rousseff, a agenda da política externa e, especialmente, a relacionada à cooperação técnica não entrou diretamente em disputa junto ao Legislativo, com exceção de críticas pontuais de parlamentares da oposição sobre a renegociação da dívida com os países africanos em 2013 (MARCONDES; MAWDSLEY, 2017).

A centralização de poderes no Executivo como a instância responsável pela política externa está legalmente embasada nos artigos 21, 22 e 84, inciso VII, da Constituição de 1988, que prevê, em certa medida, o compartilhamento do processo decisório e das ações externas entre o presidente e Ministério das Relações Exteriores (MRE). Tradicionalmente, o MRE era considerado o guardião da política externa, porém, em meados dos anos 90 isso se altera com a ascensão da diplomacia presidencial (CASON; POWER, 2005), que se torna sine qua non, especialmente, nos governos de Lula da Silva.

Esse interesse e engajamento da presidência nos temas internacionais, tanto nos governos de Fernando Henrique Cardoso (1995-2002) como nos de Lula (2003-2010), criou expectativas em relação à presidência de Dilma Rousseff. Entretanto, diferente de seu antecessor, a presidenta não manteve o mesmo grau de envolvimento com a agenda internacional, com uma queda substancial 
Cooperação Sul-Sul no governo de Dilma Rousseff (2011-2016)...

Roberto Goulart Menezes • Natalia N. Fingermann

das viagens presidenciais. Porém, embora o governo Dilma tenha mantido em linhas gerais a atuação brasileira na região e a orientação do Sul Global, o fato é que ela "deu um pouco menos de ênfase aos temas exteriores do que o governo Lula" (AMORIM, 2016), mesmo em uma região fundamental para o Brasil como a América do Sul. Essa percepção é compartilhada por pesquisadores da área de Relações Internacionais que identificam o esvaziamento da "dimensão política do comportamento brasileiro frente à região no que diz respeito à ações do Brasil como ator estruturador das instituições regionais e definidor de agendas" (SARAIVA; GOMES, 2016, p. 90). Cornetet (2014), por exemplo, demonstra que o número de viagens internacionais caiu $55 \%$ no primeiro mandato de Dilma Rousseff quando comparado com o segundo mandato de Lula da Silva. Além disso, a pesquisa destaca como "reuniões de cúpula e agrupamentos com fins específicos, não foram descontinuadas [...] [mas] as iniciativas do Brasil são, hodiernamente, ora mais "reativas" do que "ativas" (CORNETET, 2014, p. 11-12).

No caso da cooperação técnica, o ofuscamento dos projetos é resultado tanto do jogo de cadeiras ${ }^{10}$ do Itamaraty quanto do menor grau de envolvimento presidencial na política externa (FINGERMANN, 2015; 2017a). Um exemplo dessa omissão de Rousseff é o seu não comparecimento para a inauguração da Fábrica de Antirretrovirais em Moçambique, um dos projetos mais importantes implantados pela $A B C$ na área da saúde, em parceria com Fiocruz, devido ao valor dos recursos alocados e à proposta inovadora dentro da área de cooperação para desenvolvimento. Outro momento em que a ausência presidencial, e inclusive do próprio Ministro das Relações Exteriores, impacta na cooperação técnica é durante o ano de 2013, quando há os diferentes embates entre os atores da sociedade civil e a coordenação do Programa ProSAVANA. Nesse caso específico, Rousseff permaneceu distante,

\footnotetext{
$10 \mathrm{Em}$ seus dois mandatos, houve três ministros a frente do Itamaraty, sendo todos eles diplomatas de carreira, sem qualquer participação política. Primeiro, foi o Ministro Antônio Patriota (2011-2013) que foi demitido após o incidente junto ao senador boliviano. Segundo, esteve o Ministro Luiz Alberto Figueiredo (2013-2014). Por último, o Ministro Mauro Vieira (2015-2016) que saiu após o processo de ilegítimo de impeachment da presidenta. O ex-chanceler Celso Amorim e Marco Aurélio Garcia são mantidos no governo, porém o primeiro assume o Ministério da Defesa e o segundo fica com mais timidez em seu papel de Assessor Especial da Presidência da República para Assuntos Internacionais. O Embaixador Samuel Pinheiro Guimarães, chave na gestão Lula na Secretaria-Geral de Relações Exteriores, assume como Alto Representante Geral do Mercosul. No caso da $A B C$, os ministros das relações exteriores do período da gestão de Rousseff nomearam dois diretores, o Embaixador Fernando Abreu (2012-2015) e Embaixador João Almino (2015-2018).
} 
Cooperação Sul-Sul no governo de Dilma Rousseff (2011-2016)...

Roberto Goulart Menezes • Natalia N. Fingermann

focada nas questões domésticas e, principalmente, nas Jornadas de Junho, a ABC ficou isolada na articulação do Programa, pois não contava também com um forte apoio do Ministério das Relações Exteriores ${ }^{11}$, e como possui diversas limitações organizacionais, a agência não conseguiu garantir a implementação do programa naquele governo. A não construção do Laboratório em Nampula, parte integrante do Programa ProSAVANA, indica esse insucesso em termos de articulação política da ABC (Ibid, 2015).

Em relação ao Legislativo, a sua limitação na política externa ocorre devido a duas questões, uma de caráter legal e outra de caráter político. A Constituição Brasileira considera que cabe ao poder Legislativo somente um papel complementar, com a aprovação ou rejeição de atos e acordos internacionais. Nesse sentido, estudos recentes identificam o alto índice de aprovação dos atos e acordos internacionais na Câmara dos Deputados e no Senado (SILVA; SPOHR, 2016), mesmo durante o primeiro mandato de Dilma Rousseff. De acordo com os autores, a taxa de aprovação de atos e acordos internacionais foi de 98,1 \% e 96,4\% na Câmara dos Deputados e no Senado, respectivamente. Fato que indica uma continuidade no comportamento institucional do Legislativo durante o governo de Rousseff, vinculado principalmente, à limitação legal atribuída a esse órgão.

Em termos políticos, a agenda das relações internacionais fica normalmente limitada à esfera do legislativo pelo fato dessa pasta não ser considerada importante para a formação de alianças partidárias típicas do "presidencialismo de coalizão" (ABRANCHES, 1988). Nesse sentido, o poder Executivo tem autonomia na escoIha do Ministro das Relações Exteriores, sem que essa posição seja visada como uma moeda de troca política, uma vez que não trata de assuntos relevantes para a agenda local dos parlamentares (BATISTA, 2016).

11 Em agosto de 2013, há a demissão do chanceler Antônio Patriota. Logo, em 2014, o Itamaraty demonstra a insatisfação em relação ao governo de Rousseff, com a publicação de uma carta pública. Para mais informações, veja: https://www1.folha.uol. com.br/mundo/2014/09/1523783-diplomatas-criticam-anomalia-no-itamaraty.shtml 
Cooperação Sul-Sul no governo de Dilma Rousseff (2011-2016)...

Roberto Goulart Menezes • Natalia N. Fingermann

No entanto, é preciso destacar que no âmbito da CSS o Legislativo desempenha um papel importante em relação às autarquias, uma vez que cabe a esse órgão a aprovação de escritórios no exterior das executoras da cooperação técnica na esfera internacional, como o caso da EMBRAPA, Fiocruz, entre outras. Nesse aspecto, ambas as instituições receberam a aprovação do Legislativo, no começo do governo de Rousseff, embora suas atividades no exterior já ocorressem anteriormente via parcerias ou mandato presidencial. Para a EMBRAPA, a aprovação das atividades da empresa fora do território nacional aconteceu a partir da Lei $n^{\circ}$ 12.383, de $1^{\circ}$ de março de 2011, que substitui a Medida Provisória $n^{\circ} 504$ de 2010, enquanto que para Fiocruz ocorreu com a aprovação do Decreto n 355 em 2011 que aprova a Instalação da Sede do Escritório Regional da FIOCRUZ, em Maputo (Moçambique), celebrado em setembro de 2008.

Por último, é importante destacar o papel da Comissão de Relações Exteriores e Defesa Nacional (CREDN), principalmente, no sentido de garantir a aprovação dos projetos de lei de interesse do Executivo na política externa. Pesquisa realizada por Almeida (2013) demonstra que essa instância tem sido chave para a aprovação de projetos de lei, principalmente, para aqueles deputados da coalizão governista. No caso do governo de Rousseff, esse padrão de comportamento se mantém na esfera da atuação da Agência Brasileira de Cooperação, uma vez que o relatório apresentado pela comissão, no âmbito do Senado, no começo de 2016, destacava os pontos positivos da cooperação técnica e a necessidade de se estabelecer um marco legal para incrementar a sua autonomia e independência orçamental (CREDN, 2016).

No que tange às autarquias, este artigo destaca a atuação da EMBRAPA e Fiocruz, que são as entidades que representam os dois maiores setores de atuação da cooperação técnica brasileira: agricultura e saúde. Embora a presidência não estivesse tão engajada na política externa, destaca-se uma continuidade e um aprofundamento institucional da área de cooperação técnica dentro da EMBRAPA, como também da Fiocruz. Na Fiocruz, por exemplo, 
Cooperação Sul-Sul no governo de Dilma Rousseff (2011-2016)...

Roberto Goulart Menezes • Natalia N. Fingermann

após o estabelecimento do Centro de Relações Internacionais em Saúde em 2009, cria-se em 2013 a Câmara Técnica de Cooperação Internacional, com o objetivo de "prestar assessoria técnica e científica à Presidência e ao Conselho Deliberativo da Fiocruz, na área de cooperação internacional, visando à formulação e avaliação de políticas institucionais, e a promoção da articulação horizontal entre os diversos Institutos e programas da instituição" (CRIS, 2013). Além disso, é preciso ressaltar o papel da Fundação em conceber a ideia de "cooperação estruturante", com o propósito de integrar a formação de recursos humanos com o fortalecimento organizacional e desenvolvimento institucional (ALMEIDA et al., 2010), que é mantida no core dos projetos de CSS, independente do governo em questão, e foi adotada como um eixo da própria ABC.

No caso da Embrapa, a área de cooperação técnica surge somente durante o governo Lula da Silva, embora a área de cooperação internacional seja parte integrante da empresa desde a sua fundação (NASCIMENTO, 2016). Os avanços na estrutura institucional para atender a demanda de projetos de cooperação técnica são continuados durante a presidência de Rousseff, com a manutenção da Coordenadoria de Cooperação Técnica dentro da Secretaria de Relações Internacionais, dos escritórios internacionais para transferência de tecnologia aos países africanos e a continuidade de projetos bem-sucedidos, como o Cotton-4 que passou a incluir o Togo na segunda fase iniciada em 2015.

No geral, a análise dessas duas autarquias indica que internamente houve avanços institucionais e esforços para atender de maneira efetiva às demandas de cooperação técnica da $A B C$, com a instauração de práticas de cooperação fora do território nacional, além da expansão de cursos de capacitação no âmbito local. Entretanto, é necessário destacar que, no caso da Fiocruz, ainda persiste a restrição legal de manter seus funcionários por mais de três meses fora do país, o que limita, em certa medida, o andamento dos projetos de cooperação técnica em Moçambique, como a Fábrica de Retrovirais e o Banco de Leite Humano, mesmo após a formalização do escritório internacional (MARCONDES; 
Cooperação Sul-Sul no governo de Dilma Rousseff (2011-2016)...

Roberto Goulart Menezes • Natalia N. Fingermann

MAWDSLEY, 2017). Essa característica legal da Fiocruz está relacionada ao fato dela se enquadrar como uma Fundação, enquanto a EMBRAPA é registrada como uma empresa pública.

\subsection{Grupos de Interesse}

O empresariado brasileiro que esteve alinhado às diretrizes políticas do governo Lula mantém inicialmente o seu apoio a presidência de Rousseff. Porém, a coalizão produtivista e rentista que sustentou o lulismo ${ }^{12}$ fragmentou-se rapidamente pelas contradições que emergem das políticas anticíclicas de viés desenvolvimentista, seguido da promoção de ataques direto da presidência aos banqueiros e rentistas, com a politização da redução da taxa de juros e dos spreads bancários (SINGER, 2015; BASTOS, 2017). Em sequência a essas medidas, o setor produtivista - representado pela FIESP, CNI e sindicatos -, que supostamente era o maior beneficiário das políticas dilmistas, adere gradualmente à tese do bloco rentista, que apontava uma posição contrária a qualquer "intervenção" do Estado, principalmente, em relação à garantia dos direitos sociais e trabalhistas (SINGER, 2015).

Outro aspecto que contribui ainda mais para esse "racha" entre o governo e o empresariado é a Operação Lava-Jato, que afetou especialmente as empresas de construção civil, que foram aliadas-chave do governo de Lula da Silva, e angariaram muitos benefícios econômicos das relações Sul-Sul, em especial, junto à África13. Como bem aponta Bastos (2017, p. 5):

Paradoxalmente, o fato de o governo Dilma Rousseff apoiar a Lava-Jato enfraqueceu sua governabilidade em outro sentido. Políticos e empresários envolvidos em transações suspeitas tinham interesse evidente em substituir o governo por outro capaz de barrar ou limitar as apurações e patrocinar algum tipo de anistia dos crimes cometidos.

12 O lulismo é um termo cunhado pelo cientista político André Singer, que define o modelo adotado durante o governo Lula, com base em seu carisma, e na conciliação entre as diferentes classes sociais.

13 Empresas como a Odebrecht, Andrade Gutierrez, Camargo Corrêa e Queiroz Galvão expandiram seus investimentos em diversos países africanos durante esse período (VALOR ECONÔMICO, 2011). 
Cooperação Sul-Sul no governo de Dilma Rousseff (2011-2016)...

Roberto Goulart Menezes • Natalia N. Fingermann

Com a carência de apoio do setor produtivo e rentista, o governo de Rousseff busca manter a sua aproximação junto ao agronegócio, tomando as seguintes medidas: a aprovação do Código Florestal (2012), o lançamento do Plano Safra (2014) e o recuo na demarcação das terras indígenas e na desapropriação de terras para reforma agrária (ESTADÃO, 2013; FOLHA de S.PAULO, 2013; VALOR ECONÔMICO, 2014). Essas iniciativas do governo comprometem, no entanto, o apoio dos movimentos sociais ligados direta ou indiretamente ao Partido dos Trabalhadores, enfraquecendo a governabilidade de Dilma Rousseff. Além disso, esse apoio do agronegócio é fugaz, pois este logo se une aos outros setores do empresariado, quando se inicia o processo de impedimento.

Foi nesse cenário de divergência constante com o setor empresarial - produtivo, rentista e agronegócio - que Rousseff fez a proposta de vincular a cooperação técnica a uma agenda de comércio e investimento, com potenciais ganhos ao setor privado. Entretanto, é evidente que essa proposta fica restrita na esfera das ideias, pois não havia uma rede de apoio dos diferentes setores sociais para executá-la. O Caso do Programa ProSAVANA demonstra claramente isso, uma vez que houve um esvaziamento da participação do empresariado no Fundo Nacala, assim como uma queda no número de missões comerciais do agronegócio brasileiro à Moçambique, destacado pela Câmara de Comércio, Indústria, Agropecuária Brasil em Moçambique ${ }^{14}$.

Essa insatisfação com o governo de Rousseff também atinge a base social tradicional dos governos petistas, com um distanciamento do Movimento dos Trabalhadores Rurais Sem Terra (MST) e dos povos indígenas. Em entrevista dada ao Jornal Folha de São Paulo (2013), Alexandre Conceição, da coordenação nacional do MST, afirma que “O governo Dilma é refém dessa aliança com o agronegócio, que é o latifúndio modernizado, que se aliou com as empresas transnacionais", sem desapropriar os latifúndios e priorizar a balança comercial. Enquanto que no movimento indígena há uma inquietação também disseminada nos meios de comuni-

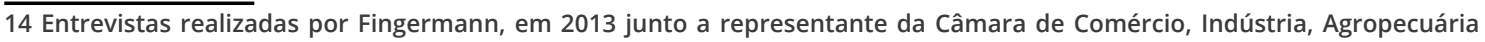
Brasil em Moçambique. 
Cooperação Sul-Sul no governo de Dilma Rousseff (2011-2016)...

Roberto Goulart Menezes • Natalia N. Fingermann

cação, devido à lentidão nas demarcações indígenas e à aprovação do Código Florestal.

Esse desalinhamento impacta na cooperação técnica, que une Organizações da Sociedade Civil aos movimentos sociais e grupos religiosos, os quais rechaçam a estratégia apresentada pela presidenta. Aqui, novamente o caso do Programa ProSAVANA demonstra a baixa capacidade do governo em unir interesses de diferentes setores sociais. Em 2013, a ONG brasileira Federação de Órgãos para Assistência Social e Educacional (FASE), liderada por Fátima Mello, promove uma série de críticas à CSS brasileira em Moçambique, denunciado intenções dos governos brasileiro e japonês em promover a usurpação de terras no norte de Moçambique, por meio do Programa ProSAVANA e o seu Fundo Nacala. Embora de fato não houvesse apoio do agronegócio ou do empresário dentro do governo, essa narrativa de land grabbing é propagada por acadêmicos brasileiros e japoneses (FUNADA-CLASSEN, 2013; NOGUEIRA; OLLINAHO, 2013; CLEMENTS; FERNANDES, 2012). E foi adotada pelos grupos sociais que organizam, em maio de 2013, uma Carta pública ${ }^{15}$ contrária ao ProSAVANA, junto às ONGS moçambicanas, brasileiras e japonesas - aliadas a movimentos sociais brasileiros, como o MST e grupos religiosos, como a Comissão Pastoral da Terra.

\subsection{Organização}

No Brasil, a estrutura organizacional da Cooperação para o Desenvolvimento internacional surge com o propósito de alocar a ajuda internacional provida dos países desenvolvidos nos anos 50, com a criação da Comissão Nacional de Assistência Técnica (CNAT). Logo em seguida, nos anos 70, o país inicia timidamente as primeiras iniciativas de Cooperação Sul-Sul, que concentram a cooperação técnica recebida e prestada a cargo da Subsecretaria

15 Para saber mais sobre as organizações e movimentos incluídos na Carta, acesse o link:-https://fase.org.br/wp-content/uploads/2016/04/C\%C3\%B3pia-de-Carta-Aberta-das-organizac\%CC\%A7o\%CC\%83es-e-movimentos-sociais-para-Detere-Reflectir-de-Forma-Urgente-o-Programa-ProSavana-corrected.pdf 
Cooperação Sul-Sul no governo de Dilma Rousseff (2011-2016)...

Roberto Goulart Menezes • Natalia N. Fingermann

de Cooperação Econômica e Técnica Internacional, vinculado ao Ministério do Planejamento, Orçamento e Gestão.

A estrutura atual é somente estabelecida no final dos anos 80, quando se cria a Agência Brasileira de Cooperação ( $A B C)$, vinculada inicialmente à Fundação Alexandre de Gusmão (FUNAG) que, em 1996, passa à Secretaria-Geral de Cooperação e Promoção Comercial do MRE. Essa vinculação da $A B C$ ao MRE que se mantém até hoje torna difícil a agência angariar fundos próprios para sua agenda de cooperação técnica. Em 1988, a agência busca criar mecanismos institucionais necessários para realizar operações contábeis e financeiras no exterior, por meio da "intermediação" operacional e metodológica do PNUD em função da falta de um ordenamento legal específico para a cooperação internacional.

Essa "intermediação" do PNUD que permite a ampliação da carteira da ABC, ao mesmo tempo, restringe-a. Pois, a própria contratação de pessoal especializado em Cooperação Sul-Sul dependente do PNUD gera uma escassez de recursos humanos fixos na agência e uma sobrecarrega aos funcionários que têm a cargo a responsabilidade de administrar também os recursos recebidos (CABRAL; WEINSTOCK, 2010).

Além disso, essa baixa institucionalização e a escassa capacidade financeira da $A B C$ é somada aos problemas recorrentes da fragmentação no processo de implementação, que é composto por uma gama de atores e "raised issues of accountability, monitoring and evaluation as well as financial responsibility" (MARCONDES; MAWDSLEY, 2017, p. 693). As dificuldades vão desde lidar com as distinções legais de cada agência executora em relação ao trânsito internacional de servidores públicos, até os choques políticos que ocorrem por não haver uma hierarquização definida entre os diferentes ministérios do governo. Por exemplo, os servidores da EMBRAPA respondem diretamente ao Ministro da Agricultura, o que pode gerar um conflito quando executam trabalhos à $A B C$. 
Cooperação Sul-Sul no governo de Dilma Rousseff (2011-2016)...

Roberto Goulart Menezes • Natalia N. Fingermann

Dessa forma, a literatura especializada sugere:

A criação de um marco jurídico e legal de atuação, o estabelecimento de um fundo para os projetos, a definição de uma carreira de agentes de cooperação para o desenvolvimento, a institucionalização de mecanismos de diálogo com atores da sociedade civil e operadores econômicos, entre outros. (LIMA; MILANI, 2016, p. 37)

Entretanto, o governo de Dilma Rousseff não teve êxito em dar andamento na consolidação de um marco legal, embora no final de seu governo o Legislativo tenha, pela primeira vez, incluído esse tema na agenda de discussão apresentado no relatório da Comissão de Relações Exteriores e Defesa Nacional (2016).

\section{Considerações Finais}

O governo de Dilma Rousseff começou em 2011 sob forte instabilidade do cenário internacional. Isso provocou mudanças nas forças políticas na esfera doméstica. As iniciativas macroeconômicas de cunho mais desenvolvimentista romperam com o pacto estabelecido entre os diferentes setores do empresariado do governo de Lula da Silva, com consequências diretas nas aspirações de incluir uma matriz de comércio e investimento dentro da esfera cooperação Sul-Sul, inclusive, da cooperação técnica.

Entretanto, sem ativismo da diplomacia presidencial e com a dispersão dos grupos de interesses, tanto empresariais quanto sociais, a Cooperação Sul-Sul desse período é marcada por desencontros, assim como aqueles entre a vontade presidencial retratada nas ideias e suas práticas. Nessa perspectiva, há desencontros entre o empresariado e seus próprios interesses, uma vez que esses optam em se afastar das iniciativas governamentais tanto na esfera nacional quanto na internacional. Por último, há desen- 
Cooperação Sul-Sul no governo de Dilma Rousseff (2011-2016)...

Roberto Goulart Menezes • Natalia N. Fingermann

contros entre a percepção das ONGs, movimentos, grupos religiosos e, inclusive acadêmicos, e as práticas empresariais dentro da CSS. Esse fato é visto, principalmente, no caso do ProSAVANA em Moçambique, no qual grupos sociais insatisfeitos com as políticas domésticas de Rousseff rechaçam as iniciativas externas, ainda que elas não tenham sido concretizadas pelo empresariado, que se encontrava alheio ao governo.

A Agência Brasileira de Cooperação, embora não tenha tido avanços no sentido de se estabelecer um marco legal, consegue encontrar uma alternativa para dar continuidade aos projetos de cooperação técnica, mesmo com as restrições orçamentárias, a partir da construção de uma carteira de cooperação trilateral. Sabe-se que os ganhos de iniciativas de cooperação trilateral ainda podem ser dúbios (FINGERMANN, 2015), contudo é preciso reconhecer que esse caminho permite que a agência mantenha a transferência de tecnologia, em áreas relevantes aos países do Sul Global, tais como a agricultura, saúde e educação. Aparentemente, essa estratégia de focar na área de cooperação trilateral foi mantida na gestão do Temer, que realizou a publicação de dois documentos que dão destaque ao tema: "Diretrizes Gerais para a Concepção, Coordenação e Supervisão de Iniciativas de Cooperação Trilateral" (2017) e o COBRADI pelo IPEA (2018). No entanto, é preciso que novas investigações sejam realizadas nesse período após o impeachment para que se possa identificar de fato quais foram as iniciativas que realmente continuaram e quais foram aquelas esvaziadas.

\section{Referências}

ABRANCHES, Sérgio. Presidencialismo de CoAlizÃo: O dilema InStituCional brasileiro. Revista de Ciências Sociais. Rio de Janeiro, v. 31, N. 1, 1988, p. 05-34. 
Cooperação Sul-Sul no governo de Dilma Rousseff (2011-2016)...

Roberto Goulart Menezes • Natalia N. Fingermann

Almeida, Celia; CAMPOS, Rodrigo P.; BUSS, Paulo et al. A concepção brasileira de cooperação Sul-Sul estruturante em saúde. Revista Eletr. de

Com. Inf. Inov. Saúde, Rio de Janeiro, v. 4, N. 1, P. 25-35, mar. 2010.

Almeida, Helga. O Congresso e a Política externa: Um Estudo sobre a CÂmara dos Deputados Brasileira no Governo lula. III Fórum Brasileiro de Pós-Graduação em Ciência Política, 2013. Disponível em: htTp://www. SCIELO.MEC.PT/PDF/RI/N50/N50A10.PDF. ACESSO EM: 10 FEV. 2019.

Almeida, Paulo Roberto de. A diplomacia do governo Lula e seu primeiro mandato: um balanço e algumas perspectivas. Carta Internacional, [S.l.], v. 2, N. 1, P. 3-10, 2007.

Almeida, Paulo Roberto de. Never before seen in Brazil: Luis Ignacio lula da Silva's grand diplomacy. Revista Brasileira de Política INTERNACIONAL, BRASÍLIA-DF, v. 53, N. 2, P. 160-177, 2010.

ALMEIDA, Paulo Roberto de. O determinismo GeOgRÁfico da DiplomaCia Sul-Sul. Blog Diplomatizzando. Disponível em: http://diplomatizzando. BLOGSPOT.COM/SEARCh/LABEL/DIPLOMACIA\%20SUL-SUl. ACESSO EM: 20 FEV. 2019.

AMORIM, Celso. Não SE PODE EXCLUIR um PAís PORQUe VocÊ NÃo GOSTA da política dele, diz Amorim. Entrevista a Sumaia Villela. Agência Brasil. 24/8/2016.

AMOrim, Celso. O Brasil e o "renascimento africano". Folha de São Paulo - Tendências e Debates, 25/05/2003.

BAstos, Pedro Paulo Zahluth. Ascensão e crise do governo Dilma ROUSSEFF E O GOLPE DE 2016: PODER ESTRUTURAL, CONTRADIÇÃO E IDEOLOGIA.

Rev. Economia Contemporânea, núM. ESP., P. 1-63, 2017.

Batista, Mariana. Quem Ganha o Que e Como Isso Importa? Alocação o ApoIo legislativo no Brasil. 10 Encontro da Associação Brasileira de Ciência Política, 30 de agosto a 2 de setembro, 2016, Belo Horizonte, MG. DISPONÍVEL EM: HTTPS://CIENCIAPOLITICA.ORG.BR/SYSTEM/FILES/DOCUMENTOS/ 
Cooperação Sul-Sul no governo de Dilma Rousseff (2011-2016)...

Roberto Goulart Menezes • Natalia N. Fingermann

EVENTOS/2017/04/QUEM-GANHA-QUE-E-COMO-ISSO-IMPORTA-ALOCACAO-MINISTERIOS-E.PDF. ACESSO EM: 10 FEV. 2019.

BBC. BRASIL PERdoA QUASE US\$ 900 MILHões EM díVIDAS DE PAíseS AFRICANOS. 25 DE MAIO DE 2013. DISPONÍVEL EM: HTTPS://WWW.BBC.COM/PORTUGUESE/NOTICIAS/2013/05/130520_PERDAO_AFRICA_MDB. ACESSO EM: 10 FEV. 2019.

CABral, L.; ShANKLAND, A. Narratives of Brazil-Africa Cooperation for Agricultural Development: New Paradigms? CBAA Working Paper 051, Brighton, UK: Future Agricultures Consortium, 2013.

CABRAL, LíDIA.; WEINSTOCK, JULIA. BRAZILIAN TECHNICAL COOPERATION FOR DeVelopment. Drivers, mechanics and future PROSPeCts. London, OVerseas DeVelopment Institute, P. 1-45, 2010.

Cason, Jeffrey W.; POWER, Timothy J. Presidentialization, Pluralization, and the Rollback of Itamaraty: Explaining Change in Brazilian Foreign Policy Making from Cardoso to Lula. International Political Science

Review / Revue internationale de sCience Politique, [S.L.], v. 30, N. 2, P. 117140, MAR. 2009.

CENTRO DE RELAÇÕES INTERNACIONAIS (CRIS). RELATÓRIO dE Atividades. Fundação Oswaldo Cruz, 2013. Disponível em: https://portal. FIOCRUZ.BR/INFORMES-E-RELATORIOS. ACESSO EM: 10 FEV. 2019.

CEPAL. Horizontes 2030. A Igualdade no Centro do desenvolvimento sustentável. Santiago: CEPAL, 2016.

Cervo, Amado. Luiz.; LeSSA, Antônio. Carlos. O declínio: Inserção internacional do Brasil (2011-2014), Rev. Bras. Polít. Int. v. 57, N. 2, P. 133-151, 2014.

Chesnais, François. A Mundialização do capital. São Paulo: E. Xamã, 1996.

Clement\$, Elizabeth Alice; FERnandes, Bernardo Mançano. Land Grabbing, A gribusiness and the Peasantry in Brazil and Mozambique. 
Cooperação Sul-Sul no governo de Dilma Rousseff (2011-2016)...

Roberto Goulart Menezes • Natalia N. Fingermann

Agrarian Sфuth: Journal of Political Economy, [S.l.], v. 2, N. 1, P. 41-69, ABR. 2013.

COMISSÃO DE RELAÇÕES EXTERIORES E DEFESA NACIONAL DO SENADO FEDERAL (CREDN). Relatório N 16. Relator: Senador Tasso JEREISSATI, 2016.

Cornetet, João Marcelo Conte. A política externa de Dilma Rousseff: Contenção na Continuidade. Revista Conjuntura Austral, v. 5, №. 24, Jun. JUL, 2014.

CORRÊA, Marcio. Prática comentada da cooperação internacional: entre a hegemonia e A busca de aUtonomia. Brasília, DF: Ed. do Autor, 2010.

Curado, Marcelo. Por que o governo Dilma não pode ser classificado como novo-desenvolvimentista? Revista de Economia Política v. 37, N. 1, 2017, P. 130-146

DOMingueS, José MaurícIo. Modernidade global e Civilização contemporânea. Para uma renovação da teoria crítica. Belo Horizonte: Editora UFMG, 2013.

eStADÃO. Índios, Agronegócio e PT: Dilemas de Dilma. 9 de JUnho de 2013. DISPONÍVEL EM: HTTPS://POLITICA.ESTADAO.COM.BR/BLOGS/ROLDAO-ARRUDA/ INDIOS-AGRONEGOCIO-E-PT-OS-DILEMAS-DE-DILMA/. ACESSO EM: 1 FEV. 2019.

EVANS, Peter. Autonomia e parceria: Estados e transformação industrial. RIO DE JANEIRO: UFRJ, 2004.

fingermanN, Natalia N. O Brasil e a Cooperação Trilateral: Um Estudo de Caso do ProSAVANA. In MARIANO, K; MENEZES, R. G; MOREIRA, H. (Eds). Mundo em Transição: Novos VÉRTICES de POder, INSTITUIÇÕES E COOPERAÇÃO, EDITORA UFGD, 2017в.

fingermanN, Natalia N. Será o fim dos projetos de Cooperação SulSul? Revista Mundorama, 2017A. 
Cooperação Sul-Sul no governo de Dilma Rousseff (2011-2016)...

Roberto Goulart Menezes • Natalia N. Fingermann

FingermanN, Natalia N. A study of Brazilian Trilateral

Development Cooperation in Mozambique: The case of ProSaVANA and ProAlimentos. FaC Working Paper 113, Brighton, UK: Future Agricultures Consortium, 2015. Disponível em: https://AsSets.Publishing. SERVICE.GOV.UK/MEDIA/57A08990Ed915d622C0002A1/WP113_FAC.PDF. ACESSO EM: 10 FEV. 2019.

FingermanN, Natalia N. A Cooperação trilateral brasileira em Moçambique - UM estudo de CASO COMPARAdo: o ProAliMENTOS e o ProSaVAna. Tese de doutorado, São Paulo, Brazil: Escola de Administração de Empresas de São Paulo, 2014.

FOLHA DE SÃO PAULO. Governo MUdARÁ AGÊNCIA DE COOPERAÇÃo. 19.07.2013. DISPONIVEL EM: HTTPS://WWW1.FOLHA.UOL.COM.BR/MUNDO/2013/07/1313410-GOVERNO-MUDARA-AGENCIA-DE-COOPERACAO.SHTML. ACESSO EM: 08 FEV. 2019.

FUnADA-CLASSEN, Sayaka. Análise do Discurso e dos Antecedentes do ProsavanA em Moçambique: Enfoque do papel do Japão, Working PAPER, TÓQUio, JAN. 2013A. DisPonível EM: HTTP://WWW. OPEN.AC.UK/TECHNOLOGY/MOZAMBIQUE/SITES/WWW.OPEN.AC.UK.TECHNOLOGY.MOZAMBIQUE/FILES/ FILES/AN\%C3\%A1 LISE\%20DO\%20DISCURSO\%20DO\%20PROSAVANA\%20 \%28Funada\%29.PdF. ACESSO EM: 13 mal. 2013.

Gonçalves, Reinaldo. Cooperação Sul-Sul, Mercosul e Relações Comerciais Bilaterais do Brasil Fracasso da Política Externa do PT. Texto para Discussão 023, Instituto de Economia, UFRJ, 2016. Disponível em: HTTP://WWW.IE.UFRJ.BR/IMAGES/PESQUISA/PUBLICACOES/DISCUSSAO/2016/TD_ IE_023_2016_GONCALVESV.2.PDF. ACESSO EM: 11 FEV. 2019.

GonçalVeS, Reinaldo. Política externa, Viagens internacionais do PRESIDENTE LULA E COMÉRCIO EXTERIOR. O FIASCO dO CAIXEIRO-VIAJANTE. TEXTO para Discussão 033, Instituto de Economia, UFRJ, 2017. Disponível em: HTTP://WWW.IE.UFRJ.BR/IMAGES/PESQUISA/PUBLICACOES/DISCUSSAO/2017/TDIE0032017gonCALVES.PdF. ACESSO eM: 11 feV. 2019. 
Cooperação Sul-Sul no governo de Dilma Rousseff (2011-2016)...

Roberto Goulart Menezes • Natalia N. Fingermann

HIRST, Monica, SOARES DE LIMA, Maria Regina \& PinHEIRO, Letícia. A POLITICA EXTERNA BRASILEIRA EM TEMPOS DE NOVOS HORIZONTES E DESAFIOS. IN: Observatório Político Sul-Americano - análise de conjuntura n. 12, dez. 2010, P.1-19.

HURRELL, Andrew. Hegemony, liberalism and global order: What space for WOUld-be GReat poWers?. International Affairs, v. 82, N. 1, P. 1-19, 2006.

INSTITUTO DE PESQUISA ECONÔMICA APLICADA- IPEA. CoOperação BRASILEIRA PARA O DESENVOLVIMENTO INTERNACIONAL (2005-2009). BRASÍLIA, DF, 2010.

INSTITUTO DE PESQUISA ECONÔMICA APLICADA- IPEA. Cooperação BRASILEIRA PARA O DESENVOLVIMENTO INTERNACIONAL (2013-2013). BRASílIA, DF, 2016.

LANCASTeR, C. Foreign aid: Diplomacy, Development, Domestic Politics. Chicago: University Chicago Press, 2007.

LEITE, I. O Governo Dilma e o futuro da Cooperação Brasileira para O desenvolvimento internacional. Revista Mundorama, 2010.

LiMA, Maria Regina Soares de. A política externa brasileira e os desafios da cooperação Sul-Sul. Revista Brasileira de Política Internacional, BrasíliaDF, v. 48, N.1, P. 24-59, 2005.

LiMA, Maria Regina Soares de.; Milani, Carlos. Política externa, geoPOLÍTICA E MODELOS DE DESENVOLVIMENTO. IN: LIMA; MILANI; MUÑOZ (ORGS). Cooperación Sur-Sur, política exterior y modelos de desarrollo en América Latina. Buenos Aires: Clacso, 2016, P. 21-39.

MARCONDES, Danilo; MAWDSLEy , Emma. South-South In Retreat? The transitions from Lula to Rousseff to Temer ANd BraziLIan DEVELOPMENT cooperation. International Affairs, v. 93, N. 3, P. 681-699, 2017.

Menezes, Roberto Goulart; Ribeiro, Claudio Oliveira. A Cooperação Sul-Sul Revisitada: A Política Externa do Governo lula da Silva e o 
Cooperação Sul-Sul no governo de Dilma Rousseff (2011-2016)...

Roberto Goulart Menezes • Natalia N. Fingermann

Desenvolvimento Africano. In: CIRCUITO DE DEBATES ACADÊMICOS, 1, ANAIS... CODE 2011, [S.L.], IPEA, 2011.

Nogueira, Isabela; Ollinaho, Ossi. From Rhetoric to Practice in South-South Development Cooperation: A case study of Brazilian interventions in the Nacala corridor deVelopment program, Working Paper, UNIVERSITY OF GENEVA, 2013.

Ribeiro, Claudio. A política africana do governo lula Tempo Social (2003-2006), Revista de sociologia da USP, SÃo PaUlo, v. 21, N. 2, P. 185209, 2010.

SARAiva, Miriam G.; Gomes, Zimmer B. Os limites da Política Externa de Dilma Rousseff para a América do Sul. Relaciones Internacionales, n. 50, 2016, P. 81-97

Silva, André Luiz Reis; SPOHR, Alexandre Piffero. A relação entre executivo e legislativo na formulação de política externa no Brasil. Relações INTERNACIONAIS, N. 50, P. 123-140, 2016.

SINGER, André. Cutucando onçAs com varas CuRTAS: O ensaio desenVolvimentista no primeiro mandato de Dilma Rousseff (2011-2014). Novos Estudos, N. 102, P. 39-67, 2015.

VAlOR ECONOMICO. Plano Safra agrada, mas não garante voto. 2014. DISPONIVEL EM: HTTPS://WWW.VALOR.COM.BR/AGRO/3554102/PLANO-SAFRA-AGRADA-MAS-NAO-GARANTE-VOto. ACESSO EM: 1 FEV. 2019.

VIGEVANI, Tullo; CePAlUni, Gabriel. Lula's Foreign Policy and the Quest for Autonomy through Diversification. Third World Quarterly, [S.L.] V. 28, N.7, P. 1309-1326, Sep. 2007. 